\title{
GESTIÓN URBANA Y REGULARIZACIÓN DEL HÁBITAT POPULAR EN LA PLATA, ARGENTINA. Contradicciones de las políticas con efectos territoriales
}

\author{
Mariana Relli Ugartamendía \\ CIG IdIHCS FaHCE UNLP CONICET - Argentina \\ Directora: Beatriz Cuenya - Codirectora: Patricia Pintos \\ mrelli@fahce.unlp.edu.ar
}

\section{RESUMEN}

Frente al crecimiento y densificación del hábitat popular urbano en la provincia de Buenos Aires, Argentina, se han implementado iniciativas gubernamentales de regularización para radicar a la población allí donde esté asentada, regularizar la tenencia de los inmuebles y facilitar el acceso a la propiedad. Desde hace tres décadas se utilizan distintos instrumentos para atender las dimensiones dominial y urbanística de la irregularidad. En esta ponencia se analiza el tratamiento dado a la irregularidad en el municipio de La Plata (capital de la provincia de Buenos Aires) y su (no)diálogo con la política urbana. La consolidación de dos ventanillas desde donde la gestión pública encara el ordenamiento territorial -la de la ciudad formal y la de la ciudad informal- ha cristalizado en un andamiaje institucional que refuerza el tratamiento ex post de la irregularidad, sin atender sus causas.

Palabras clave: hábitat popular - irregularidad - regularización - política urbana

\begin{abstract}
In the face of the growth and the infill of the urban popular environment in the Buenos Aires province, Argentina, governmental initiatives of regularization have been implemented in order to abide the population where there is settled down, to regularize the building possession, and to make easier the property access. Since three decades, different resources have been used to deal with the territory and urban dimensions of the irregularity. In this presentation, the irregularity treatment at the city of La Plata (capital of the Buenos Aires province) and its (non-)dialog with the urban politics are analyzed. The consolidation of two windows from where the public administration face the territorial legal system -both formal and informal cities- has taken shape in an institutional framework that strengthens the ex post treatment of the irregularity, without caring for its causes.
\end{abstract}

Key words: popular settlements - irregularity - regularization - urban policy 


\section{INTRODUCCIÓN}

Este trabajo presenta sintéticamente una de las cuestiones analizadas en la Tesis de Doctorado en

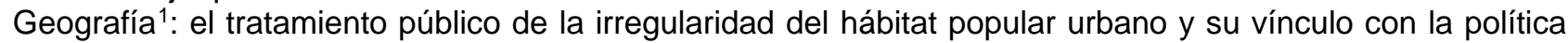
urbana en el partido de La Plata, provincia de Buenos Aires, Argentina.

Se realiza un breve repaso conceptual sobre la irregularidad del hábitat popular como constitutiva de las ciudades latinoamericanas y la regularización como forma de reconocimiento público de las dificultades estructurales del capitalismo periférico para proveer de viviendas al conjunto de la sociedad.

Se exponen la orientación general de la política de regularización en la provincia de Buenos Aires y los instrumentos que la constituyen, así como los roles que asume el Estado en sus opciones de resolución de la problemática. El estudio de caso se aborda a partir de la presentación general del hábitat popular en el municipio de La Plata y la identificación de situaciones de irregularidad a tratar desde la política de regularización, para posteriormente observar el derrotero de la política urbana y la política de regularización y sus resultados. Se concluye que la consolidación de dos ventanillas desde donde la gestión pública encara el ordenamiento territorial -la de la ciudad formal y la de la ciudad informal- ha cristalizado en un andamiaje institucional que refuerza el tratamiento ex post de la irregularidad, alimentándola y sin poder atender sus causas.

En el transcurso de la investigación se trabajó con diferentes fuentes secundarias (información de organismos públicos y privados, documentos oficiales, literatura especializada), se realizaron más de treinta entrevistas a informantes clave (personal técnico y actores políticos de los tres niveles de gobierno) y se recurrió a la fotointerpretación para la confección de cartografía.

\section{LA IRREGULARIDAD COMO PARTE CONSTITUTIVA DE LA CIUDAD LATINOAMERICANA Y LA REGULARIZACIÓN COMO RESPUESTA GENERALIZADA}

El hábitat popular urbano ${ }^{2}$ está constituido por los asentamientos autoproducidos progresivamente por los sectores sociales con recursos insuficientes para acceder a la vivienda urbana mediante las vías formales: el mercado (compraventa o alquiler) y los programas habitacionales públicos. En sus fases de producción (acceso al suelo, construcción) suele caer en el incumplimiento de las normativas que gobiernan la producción y organización de hechos físicos en la ciudad y/o las relaciones de propiedad, de allí la identificación generalizada entre urbanización popular e irregularidad o informalidad ${ }^{3}$. Acordamos con Duhau $(1998,2002)$ en que, con el calificativo de irregular o informal no se están describiendo características físicas de las urbanizaciones, sino relaciones problemáticas con el orden jurídico vigente respecto de la propiedad ${ }^{4}$ (dimensión dominial) y con la normativa que conforma al orden urbano legítimo (dimensión urbanísticaambiental).

La irregularidad desde hace tiempo dejó de ser una excepción para convertirse en una forma latinoamericana de producir espacio urbano que coexiste con la producción privada, la producción pública y la producción por encargo (Schteingart, 2001; Pírez, 1995; Rodríguez y Di Virgilio, 2007; Jaramillo, 2012; Pírez, 2016). La defensa de la propiedad privada, la rigidez de los parámetros urbanísticos y el laissez faire en el mercado de suelo se señalan como los responsables de su existencia, junto a la insuficiencia de ingresos, las inserciones laborales precarizadas e inestables de la población y la oferta de créditos nula para estos sectores (Fernandes, 2008; Herzer et.al., 2008; Abramo, 2011).

A la irregularidad del hábitat se la ha tratado con medidas ex ante o preventivas y, mayoritariamente, con medidas de regularización. Las primeras consisten en intervenciones públicas para que exista una oferta formal de suelo al alcance de las posibilidades de las familias que podrían ser potenciales ocupantes o compradoras en el mercado irregular; son encaradas directamente por el Estado o de manera indirecta a

1 Política de regularización del hábitat popular urbano: provincia de Buenos Aires y partido de La Plata, 1983-2015. Tesis de Doctorado en Geografía, FaHCE, UNLP.

2 También denominado urbanización popular o urbanización inversa (Duhau 1998; Pírez 2016).

3 Se denominará irregulares o informales, indistintamente, a las actividades generadoras de ingresos o bienes para cubrir necesidades de quienes quedan afuera de los mecanismos formales/regulares, reservando el calificativo de ilegal para las actividades delictivas (por ejemplo, fraccionamiento de suelo llevado a cabo por un agente económico, que incumple normativa para maximizar ganancias en beneficio propio).

4 Derechos de propiedad que, en sociedades regidas por el derecho positivo, como en América Latina, son garantizados si el objeto físico (lote, en este caso) se encuentra identificado y registrado en el catastro correspondiente. 
través de medidas de aliento a la producción de suelo urbano (exenciones impositivas) o de castigo a la retención especulativa de inmuebles. Por su parte, la regularización pretende acomodar dentro de la normativa lo que se ha producido por fuera:

- regularización dominial: formalización de la subdivisión predial, reconocimiento de los/as poseedores/as de cada parcela y otorgamiento de títulos formales que den validez jurídica a los actos de posesión de los/as pobladores/as ${ }^{5}$;

- regularización urbanística y ambiental: introducción de obras de infraestructura, redes de servicios públicos y reacomodamiento parcelario. Esta acción implica legitimar el proceso de urbanización previo (loteos, subdivisiones, construcciones), acomodar la estructura urbana existente y resolver caso a caso las incompatibilidades entre usos públicos y privados del espacio urbano.

Ahora bien, en la misma acción de regularización de situaciones concretas (con sus mayores o menores dificultades en el plano dominial y en el urbanístico), regularizar también es exceptuar casos conflictivos del cumplimiento de la normativa. La recurrencia a la excepción puede convertirse en un ejercicio sistemático que permite ignorar el componente urbanístico de la tarea de regularizar -sin dudas, el más oneroso y el que redunda directamente en las condiciones materiales de los barrios y en la calidad de vida de sus habitantesy dar paso a la titularización sin la adecuación urbanística. De alguna manera, la política de regularización se presenta como el modo de reconocer la materialización urbana de la producción del espacio residencial bajo la lógica de la necesidad (Pírez 1995) a través de medidas de excepción, en franca contradicción con los planteos de una política urbana constituida por un conjunto de normas que rigen la producción regular de suelo y vivienda en la ciudad y que enmarcan el accionar de los agentes intervinientes: promotores inmobiliarios, Estado, familias con distinto poder adquisitivo.

Las opciones preventivas han sido escasamente implementadas en América Latina mientras que la regularización se fue constituyendo en política en varios países de la región a partir de la confluencia de recomendaciones de organismos internacionales, demandas de organizaciones de pobladores/as e iniciativas de actores políticos desde inicios de la década del '90. Los objetivos generales que la han impulsado son: la intención de aliviar la pobreza y de asegurar la tenencia de la tierra y la vivienda a lo/as pobladore/as, la integración de los barrios irregulares al resto de la ciudad mejorando sus condiciones urbanas y ambientales, y en un segundo plano, la igualdad de género (protección de la tenencia de la vivienda a las mujeres) y la conversión de lo/as habitantes de barrios irregulares en contribuyentes al erario público y en clientes de las empresas prestadoras de servicios (Clichevsky, 2003, 2006; Fernandes, 2008).

\subsection{Política de regularización en la provincia de Buenos Aires: orientación general y caja de herramientas}

La trayectoria del procesamiento estatal de la irregularidad en Buenos Aires comienza con la entrada de la cuestión en la agenda política a fines de la década del '80 y continúa con renovada vigencia hasta la actualidad. Las iniciativas en clave preventiva han sido muy escasas y sin impactos en la reducción del problema. Durante tres décadas se han ido sumando instrumentos para atender las especificidades de la irregularidad conforme emergían las demandas sociales o iniciativas de los actores políticos, y se fue constituyendo una suerte de caja de herramientas para regularizar de la que se echa mano en distintas circunstancias y según las características de cada caso.

La dimensión dominial de la irregularidad es la que ha presentado mayor complejidad y la que ha signado el perfil de los instrumentos de regularización, forjados fundamentalmente para atender las especificidades marcadas por las formas de acceso a los inmuebles de las urbanizaciones populares: adquisición regular inconclusa ${ }^{6}$, ocupación/toma ${ }^{7}$ y adquisición irregular ${ }^{8}$. En el gráfico 1 se presentan estas modalidades de acceso al suelo, las situaciones de irregularidad que se dan dentro de cada una de ellas y los instrumentos de regularización utilizados ante cada caso.

5 Escritura pública (asocia un inmueble determinado con uno o varios titulares) y derecho real de uso (mantiene la propiedad de la tierra en manos del Estado y cede formalmente su uso a un particular).

6 Compraventas a plazos en loteos populares y entrega de viviendas públicas sin concretar escrituración, cesión de inmuebles estatales bajo pago de canon de ocupación con altos niveles de morosidad en los pagos.

7 Ingresos en los inmuebles sin consentimiento de sus titulares (propiedades públicas y privadas).

8 Compraventas en mercados irregulares de suelo y vivienda, loteos clandestinos (producidos bajo la lógica capitalista, pero por fuera de los parámetros legales) y viviendas sociales que ingresan en circuitos mercantiles irregulares. 


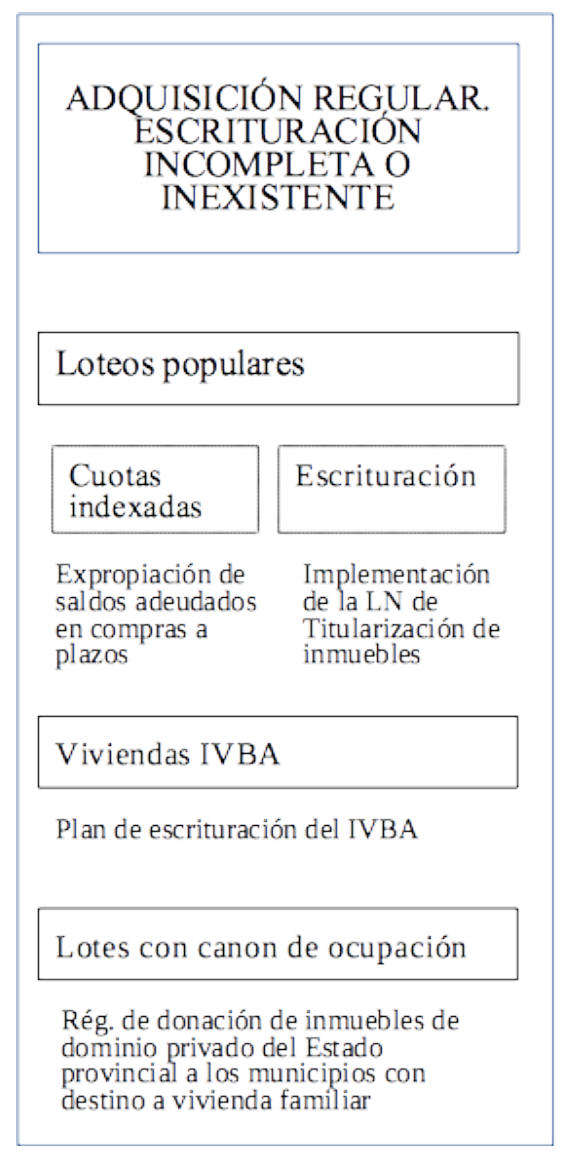

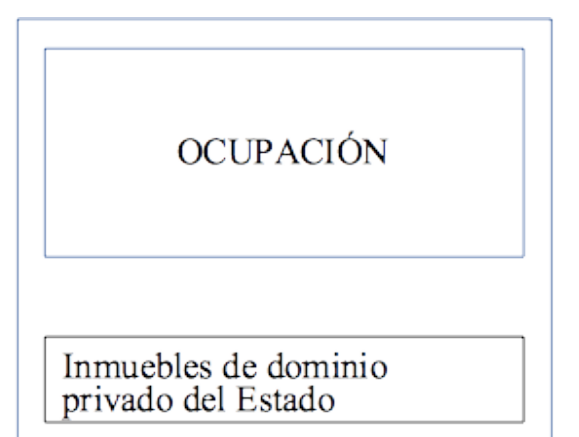

Rég. de los inmuebles de dominio municipal y provincial

Leyes ad hoc

Inmuebles de dominio privado

Reglamento de erradicación o urbanización de áreas ocupadas

Expropiaciones

Compra de tierras

Condonación de deudas impositivas a cambio de inmuebles

Prescripción administrativa

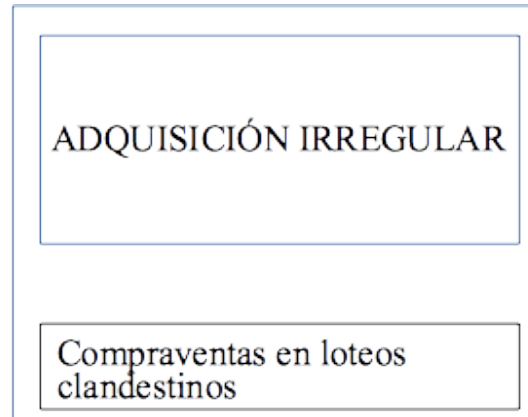

Implementación de la LN de Titularización de inmuebles

Expropiaciones

Compraventas de viviendas IVBA

Plan de escrituración del IVBA

Gráfico 1. Provincia de Buenos Aires. Instrumentos de regularización según formas de acceso a los inmueblesElaboración propia.

El perfil predominante de todas las medidas adoptadas, más allá de las situaciones que las originaron y de sus matices, es el de operatorias que tienen como objetivos la transferencia en propiedad de la tierra ocupada o adquirida irregularmente y la escrituración individual en favor de lo/as habitantes. Se evidencia una fuerte identificación entre regularización y titularización, y un tratamiento individualizado del problema (familia por familia o lote por lote), aunque en ocasiones surja de operativos a escala barrial.

Frente a distintas situaciones, el Estado provincial tiende a adoptar roles para facilitar el arribo al objetivo de la escrituración:

- Estado vendedor: en casos de inmuebles de dominio privado del Estado, la opción preferencial ha sido la transferencia en venta financiada a lo/as habitantes.

- Estado mediador: en casos de inmuebles de dominio privado, se han instrumentado mecanismos de adquisición de ese suelo para posterior transferencia financiada a sus habitantes. En ese rol, no ha afectado intereses de quienes ostenten la titularidad de los inmuebles, más allá de su ausentismo, descuido o espera especulativa.

- Estado escriturador: para casos de interrupción del circuito mercantil formal o de registración e, incluso, para cubrir déficits de acceso a la justicia de familias que no pueden afrontar los costos de las transacciones o sucesiones formales. Podríamos colocar aquí también el interés por regularizar situaciones que son producto del mismo accionar del Estado, tal es el caso de las viviendas construidas por el Instituto de la Vivienda de la provincia (IVBA), paridas irregulares cuando los tiempos electorales han marcado la agenda (Relli, 2017).

Los problemas urbanísticos y ambientales nunca fueron obstáculos reales a la regularización; en la mayoría de los instrumentos aparece la excepción como modo de atenderlos. Este es otro elemento que permite afirmar la primacía de lo dominial por sobre las condiciones materiales de los barrios, puesto que esas 
excepciones refieren a los aspectos que hacen a la calidad urbanística y ambiental ${ }^{9}$. El tratamiento de la dimensión urbanística sólo ralentizó los procesos -en ocasiones, muchos años- lo que sí puede leerse como causal de la generación de nuevas irregularidades.

Los organismos con competencias en regularización de la urbanización popular pertenecen al nivel provincial $y$, a pesar de que los instrumentos son aplicados para atender casos que, necesariamente, están emplazados en territorio municipal, el rol de los gobiernos locales queda supeditado y reducido a dar información a quienes la requieren, hacer o apoyar gestiones en organismos provinciales, visar planos cuando avanzan los procesos de regularización urbanística, organizar actos públicos de firma o entrega de actas y escrituras, etc.

\section{LA PLATA: HÁBITAT POPULAR Y EXPRESIONES DE LA IRREGULARIDAD}

La ciudad de La Plata fue fundada para ser capital de la provincia de Buenos Aires en el año 1882, planificada desde el origen, con un trazado que intentó responder a los lineamientos del higienismo imperante en los ámbitos vinculados al urbanismo y la arquitectura a fines del siglo XIX. Hoy es un municipio de 654.324 habitantes y 926 kilómetros cuadrados de superficie, forma parte del aglomerado Gran La Plata junto a Berisso y Ensenada, y es una de las ciudades más importantes de la provincia tanto por ser asiento de las dependencias del gobierno provincial, como por su oferta educativa, sanitaria, recreativa, cultural, comercial, presencia industrial y de producción intensiva de flores y hortalizas. El mapa 1 muestra la extensión del municipio, su emplazamiento, las localidades que lo conforman y la expansión sostenida del tejido urbano presentada en cortes temporales entre 1892 y 2011.

A pesar del impulso inicial planificador, los agentes de las decisiones políticas y los propietarios de la tierra determinaron la composición de la población del casco fundacional y su periferia desde su creación. El acceso al suelo se dio predominantemente a través de la compra de lotes cuya oferta fue marcando el perfil de habitantes de cada sector de la ciudad: el casco fundacional reservado para sectores de mayor poder adquisitivo y las localidades del eje norte para segundas residencias (Gonnet, City Bell y Villa Elisa), mientras que en el resto de la periferia operaba el mercado de loteos populares.

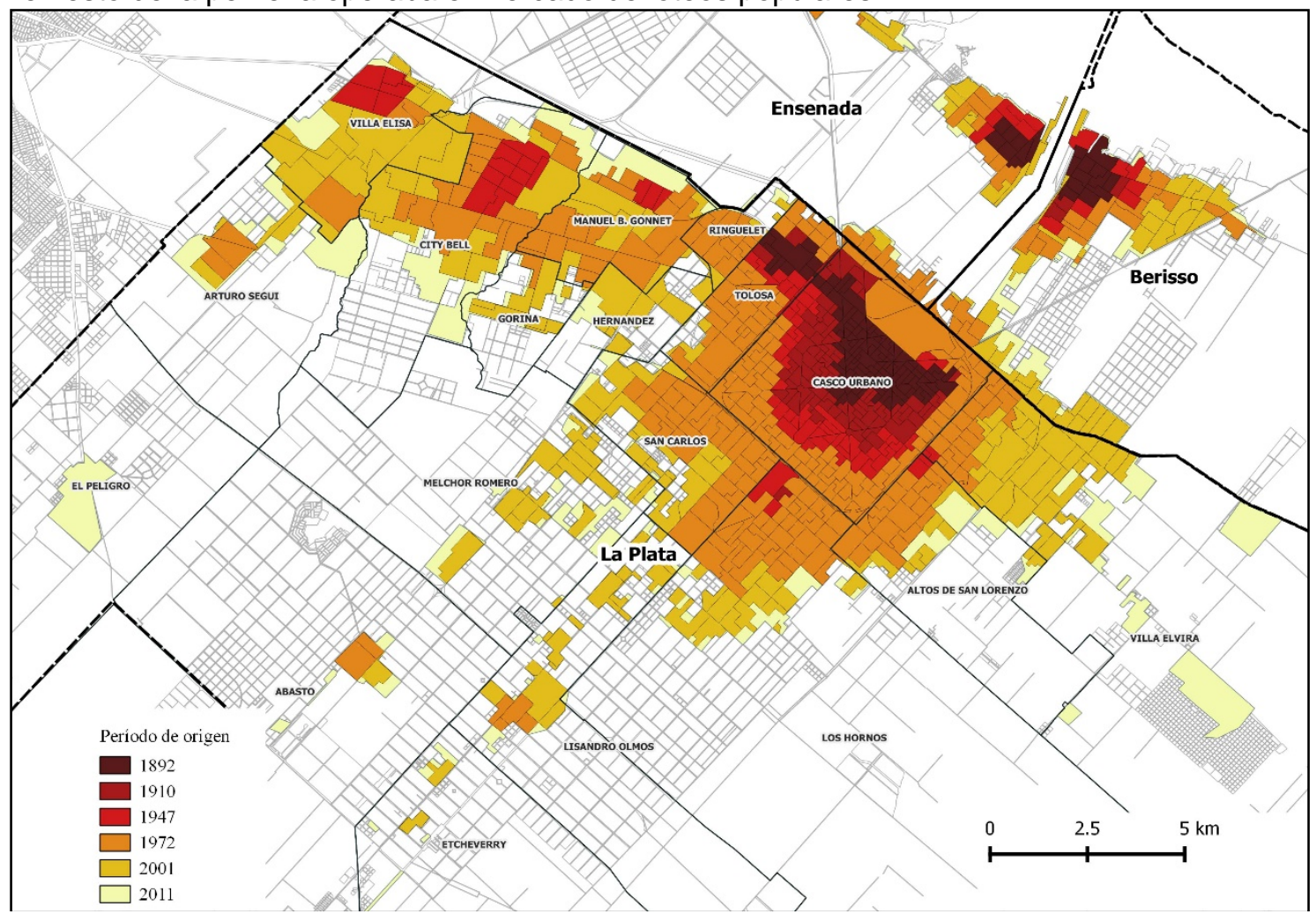

Mapa 1. La Plata. Crecimiento del tejido urbano por cortes temporales, 1892-2011

Elaboración propia en base a Lineamientos Estratégicos para la Región Metropolitana (SSUV, 2007) y fotointerpretación de imágenes de Google Earth (2013).

9 Cabe diferenciar dentro de estas generalidades al Régimen de Reconstrucción Urbana, al Régimen de integración sociourbana de villas y asentamientos y al Programa de Mejoramiento de Barrios, iniciativas de muy bajo impacto que no revierten las características generales de la política. Opciones caras frente a la política barata, masiva y de más rápida capitalización política de la titularización. 
La periferia desprovista de todo atributo urbano fue el lugar asignado a los sectores de escasa capacidad de pago. Allí, las subdivisiones se dieron de dos maneras: hasta 1930, siguiendo el trazado del ferrocarril y conforme se iban fundando pueblos en torno a las estaciones ${ }^{10}$, y entre 1930 y 1970 (cuando se concretó la primera ordenanza de subdivisión de suelo según usos en La Plata), mediante los parcelamientos de quintas y chacras, sin ningún requerimiento de servicios, que se dieron de manera indiscriminada y facilitados por las vías de acceso al centro orientadas hacia el transporte automotor.

Las familias de menos ingresos accedieron a la tierra hasta la década del ' 70 mediante la compra a plazos en loteos populares, con la posterior construcción de viviendas mediante autoconstrucción, producción por encargo o combinaciones de ambas. Cierta franja de familias trabajadoras accedió a la vivienda en el marco de programas habitacionales públicos, en conjuntos localizados mayoritariamente en la periferia. La sanción en 1977 del Decreto Ley de Ordenamiento Territorial y Usos del Suelo ${ }^{11}$ en la provincia de Buenos Aires vino a poner fin a la producción legal de tierra subdividida de muy baja calidad urbanística y desprovista de infraestructura, y estableció estándares para la subdivisión de suelo que repercutieron en los precios. Esto, sumado al desempleo y deterioro de los salarios que comenzó a vivirse desde mediados de los '70, desató un proceso de distanciamiento -una brecha hasta hoy insalvable- entre la capacidad de pago de los sectores trabajadores y los precios del suelo.

La existencia durante más de tres décadas de oferta de tierra accesible al bolsillo de los sectores de bajos ingresos explica la baja incidencia (y la expansión más tardía respecto de otros países de la región) de la irregularidad producto de las ocupaciones de tierra y de las compraventas en loteos clandestinos. Pero el fin del ciclo del loteo popular significó el fin del acceso al suelo de estos sectores a través del mercado formal, fenómeno observado en toda el Área Metropolitana de Buenos Aires (AMBA) ${ }^{12}$ y en el Gran La Plata.

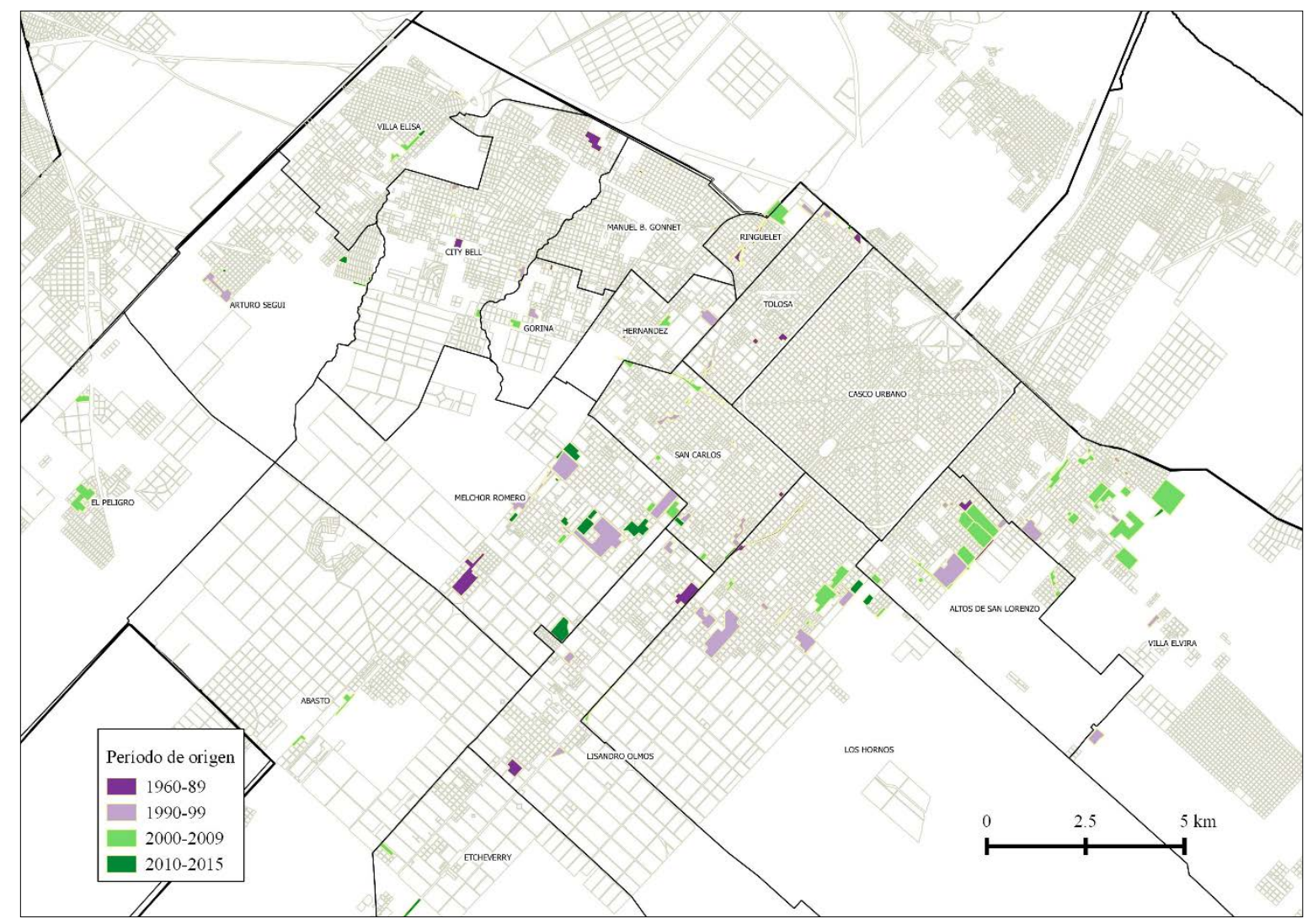

Mapa 2. La Plata. Villas y asentamientos según períodos de formación Elaboración propia en base a RPPVAP (2015).

10 La Ley 3487 de 'Fundación de Pueblos' del año 1913 establece porcentajes de suelo para equipamiento, anchos y orientación de calles, exige certificación de agua en napas, pero no extensión de servicios.

11 Decreto Ley 8912/77.

12 Conformada por la Ciudad Autónoma de Buenos Aires y 24 municipios que la circundan. 
Conforme se fueron consolidando las dificultades de acceso formal al suelo, se extendieron las ocupaciones de inmuebles y la formación de villas y asentamientos ${ }^{13}, y$, posteriormente, las compraventas en el mercado informal. El mapa 2, construido a partir de información del Registro Público Provincial de Villas y Asentamientos Precarios de la provincia (RPPVAP, 2015), muestra su presencia en el partido de La Plata, con su extensión actual y según el periodo en el que se formaron. Puede observarse que en las décadas del '70 y ' 80 , villas y asentamientos eran escasos, se emplazaban sobre tierra periférica vacante ${ }^{14}$ y espacios urbanos intersticiales en zonas cercanas al casco fundacional. Entrada la década del ' 90 , ya se evidencia una extensión del fenómeno que se agrava visiblemente en los años 2000, empeorándose, además, las condiciones de emplazamiento de las ocupaciones, formadas en su mayoría sobre áreas inundables y suelo degradado (Del Río y González, 2017). El gráfico 2 muestra el crecimiento sostenido de las villas y asentamientos en el partido de La Plata (en 2015 se contaban 31 villas y 96 asentamientos), el empeoramiento de las condiciones de emplazamiento y el aumento de los hogares que en ellos habitan.

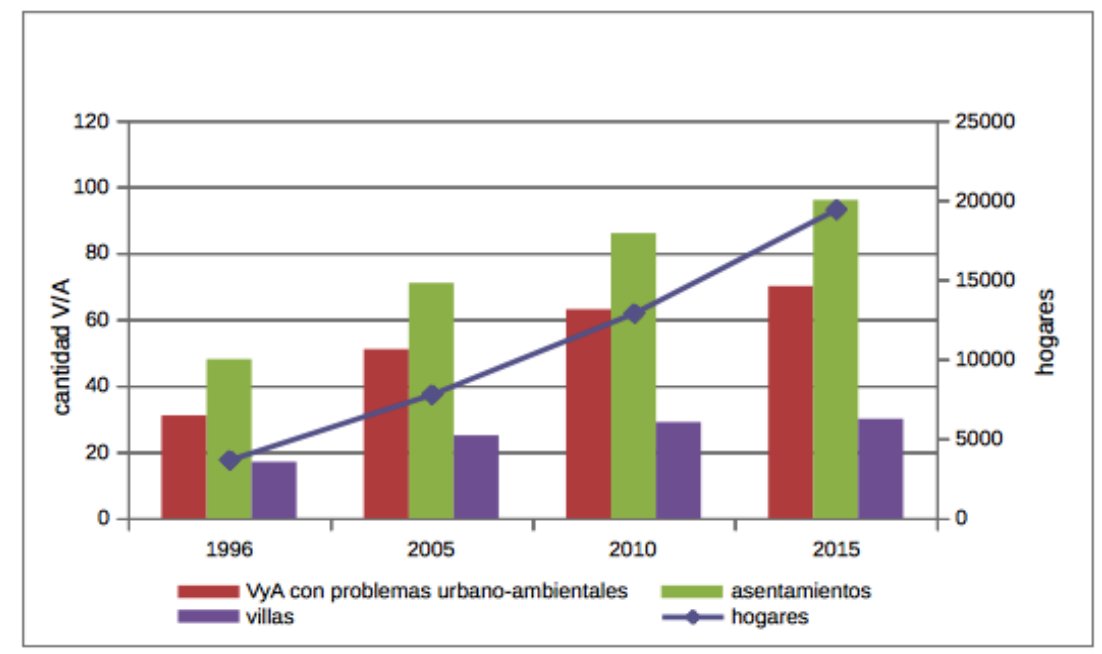

Gráfico 2. La Plata. Cantidad de villas y asentamientos y crecimiento de hogares en ellos en cuatro cortes temporales.

Elaboración propia en base a RPPVAP (2015), Del Río y González (2017) y fotolectura de P. González (2017).

El cruce de información respecto del hábitat de los sectores populares en La Plata permitió identificar las situaciones específicas de irregularidad dominial y urbanística-ambiental que se presentan en el municipio y que se han abordado desde la política pública. Hasta mediados/fines de la década del ' 90 , el cuadro de la irregularidad estaba conformado por los casos de compraventas en loteos populares que no habían llegado a escriturarse por la desaparición de las empresas loteadoras (quiebras o retiros de la actividad). Mucho de ese suelo, subdividido legalmente y sin ocupación efectiva, se ofrecía como oportunidad frente a las necesidades de las familias imposibilitadas de acceder de manera regular, dando lugar a ocupaciones de distinta intensidad en parcelas dispersas y fracciones subdivididas. A éstas se sumaron las tomas de tierras sobre áreas de reserva destinados a equipamientos que nunca se concretaron. También cabe mencionar los casos de cesión de lotes de dominio público mediante pago de canon de ocupación y la adjudicación de viviendas en el marco de programas habitacionales públicos, éstos, si bien no fueron inicialmente irregulares, tuvieron tratamiento desde la política de regularización para efectivizar su transferencia en venta y escrituración.

Durante la segunda mitad de los años '90, pero sobre todo ya entrada la primera década del 2000, la contracara del agravamiento de las condiciones de acceso al suelo y la vivienda complejizó aquel panorama inicial a partir de dos elementos centrales: la extensión de las ocupaciones de suelo vacante y de viviendas públicas (muchas de ellas inconclusas) y la introducción de las relaciones mercantiles en la producción de

13 Las villas se forman a partir de la sumatoria de construcciones sobre suelo intersticial libre y sin seguir el tejido urbano circundante, con pasillos y tramas intrincadas; los asentamientos surgen en gran parte por ocupaciones organizadas de tierras de escaso valor inmobiliario, sin infraestructura, sobre las que lo/as habitantes diseñan tramas similares a las de la ciudad formal, respetando espacios de circulación, amanzanamiento, tamaño de lotes, espacios para equipamiento, etc. todo ello da cuenta de organización, experiencias urbanas previas e intenciones de establecerse en el lugar de manera definitiva (Cravino y Varela 2008).

14 Terrenos desocupados (lotes particulares o con destino a equipamiento) en loteos aprobados antes del DL 8912 y terrenos lineales de vías del ferrocarril en desuso. 
urbanización popular. Entonces, se sumaron a los casos ya existentes, las irregularidades producto de transferencias de inmuebles sin registrar, el fraccionamiento irregular de suelo de uso rural, las compraventas de suelo ocupado o fraccionado ilegalmente y la densificación y extensión de las ocupaciones preexistentes, incluso de las que estaban en procesos de regularización. También cabe resaltar la producción de irregularidad por parte del mismo Estado en la implementación de programas habitacionales.

En el cuadro 1 se exponen los tipos de irregularidad observados en La Plata, agrupados según las formas de acceso al suelo y según las etapas en las que fueron emergiendo; la intención es mostrar sintéticamente la heterogeneidad de casos que constituyen lo que de manera general se denomina irregularidad del hábitat popular urbano y así apoyar la lectura del texto. También interesa destacar la aparición de nuevas situaciones de irregularidad que se fueron sumando a las preexistentes desde mediados/fines de los ' 90 , cuando la política de regularización ya se estaba implementando desde hacía más de una década.

\begin{tabular}{|c|c|c|}
\hline \multicolumn{3}{|c|}{ Tipos de irregularidad } \\
\hline Acceso & Hasta mediados/fines de la década del '90 & Desde mediados/fines de la década del '90 \\
\hline $\begin{array}{l}\text { Adquisición } \\
\text { reqular }\end{array}$ & $\begin{array}{l}\text { Parcelas de dominio público cedidas mediante pagc } \\
\text { de canon de ocupación }\end{array}$ & $\begin{array}{l}\text { Compraventas de macizos rurales con fines de futura } \\
\text { subdivisión legal }\end{array}$ \\
\hline $\begin{array}{l}\text { Interrupción del } \\
\text { circuito } \\
\text { mercantil formal } \\
\text { o de registración }\end{array}$ & $\begin{array}{l}\text { Compraventas en loteos populares previos al DL } \\
8912 / 77 \text { que no llegaron a escriturarse: parcelas } \\
\text { dispersas en localidades periféricas al casco } \\
\text { fundacional } \\
\text { - Posesión a la que se accedió en el marco de un } \\
\text { programa público: viviendas en conjuntos }\end{array}$ & $\begin{array}{l}\text { - Posesión a la que se accedió en el marco de un programa } \\
\text { habitacional público: viviendas en conjuntos }\end{array}$ \\
\hline Ocupación & \begin{tabular}{|l} 
Dominio público: \\
Suelo de reserva para equipamientos: parcelas \\
dispersas en áreas de expansión residencial
\end{tabular} & - Viviendas de programas habitacionales públicos \\
\hline & $\begin{array}{l}\text { Dominio privado: } \\
\text { - Parcelas en loteos: dispersas en localidades } \\
\text { periféricas }\end{array}$ & $\begin{array}{l}\text { - Parcelas en loteos: dispersas en localidades periféricas } \\
\text { - Fracciones periféricas subdivididas vacantes } \\
\text { - Fracciones rurales vacantes }\end{array}$ \\
\hline \begin{tabular}{|l} 
Adquisición \\
mercantil \\
irregular
\end{tabular} & & $\begin{array}{l}\text { - Compraventas de terrenos en fraccionamientos ilegales } \\
\text { sobre tierra vacante subdividida (loteos) } \\
\text { - Compraventas de terrenos en fraccionamientos ilegales de } \\
\text { macizos (loteos pirata) } \\
\text { - Compraventas de viviendas construidas en el marco de } \\
\text { programas habitacionales públicos }\end{array}$ \\
\hline
\end{tabular}

Cuadro 1. La Plata: Tipos de irregularidad del hábitat popular urbano según formas de acceso a los inmuebles y etapas de aparición

Elaboración propia.

\section{LAS DOS VENTANILLAS}

Tal como están planteadas las incumbencias en materia de ordenamiento territorial en la provincia de Buenos Aires, los municipios deben ceñir su planeamiento a lo establecido por el DL de Ordenamiento Territorial y Usos del Suelo. Los gobiernos locales, además, tienen cierto margen de autonomía para actuar sobre el territorio utilizando los instrumentos de gestión territorial que están plasmados en los marcos normativos provinciales para, por ejemplo, orientar el crecimiento de la ciudad y los usos del suelo, e intervenir en el mercado de suelo.

En La Plata se han identificado dos líneas institucionales municipales de intervenciones en el territorio: la de la ciudad formal y la de la ciudad informal. Por un lado, la Dirección de Planeamiento Urbano (DPU) que históricamente ha sido la que ha comandado la política urbana, en tanto orientación, limitación o habilitación del despliegue de la actividad inmobiliaria privada y la obra pública, y por otro lado, los organismos que han atendido al hábitat popular desde la regularización: la Casa de Tierras (1996-2003), la Subsecretaría de Tierras (2003-07) y la Dirección de Regularización (2007-15), acompañantes de la política gestada desde los organismos provinciales y sin diálogo con la política urbana, de ahí la identificación de "dos ventanillas" desde la que emanan políticas con efectos territoriales que a veces resultan contradictorias o conflictivas entre sí.

\subsection{La ciudad formal: orientación general de la política urbana}

En poco más de tres décadas en las que se sucedieron ocho gobiernos democráticos, se han identificado tres 
fases en la gestión territorial de la ciudad formal, en función de las tareas asumidas por la DPU y la orientación de la normativa plasmada en los distintos Códigos de Ordenamiento Urbano ${ }^{15}(\mathrm{COU})$ :

\section{El municipio se inicia en las tareas de ordenamiento territorial, la irregularidad no es un tema de agenda estatal, $1983-1991^{16}$}

Al asumir el gobierno democrático y durante los dos primeros mandatos, la DPU fue una oficina marginal del municipio, con muy poco personal capacitado en planeamiento, escaso presupuesto y con tareas acotadas al visado de expedientes de solicitudes de subdivisión de suelo o aprobación de diferentes usos. Fueron años de continuidades en la transformación del casco fundacional, iniciada décadas atrás (Sessa, 1995; Garnier, 1995), con reemplazos de viviendas originales por edificios y viviendas modernas, extensión de las vías comerciales en el área central y adaptación de la circulación al tránsito vehicular particular. La periferia crecía a partir de la ocupación regular e irregular de tierra previamente subdividida, consolidando la superposición de diferentes usos (productivo primario, industrial, residencial, extractivo, etc.) y generando áreas de "tensiones ambientales" (Resa 1995).

La problemática de la irregularidad del hábitat popular urbano en La Plata era por entonces muy incipiente y restringida a algunas villas y asentamientos de escasa población. Es decir, el municipio no tenía frente a sí el fenómeno masivo que se observaba en otras ciudades latinoamericanas y, también por eso, las tareas de la DPU quedaron orientadas desde el vamos a la función técnica de habilitar y ordenar el desempeño de los agentes inmobiliarios y propietarios del suelo.

\section{Apuesta por la planificación como herramienta de gestión territorial, 1991-2007"17}

Las cuatro gestiones consecutivas de J. Alak al frente del municipio posicionaron a la DPU como un organismo con presencia fuerte en la gestión del ordenamiento territorial; fue ampliando sus competencias y consolidando equipos con recursos humanos y tecnológicos ${ }^{18}$; fue el periodo en el que se expresó con más fuerza la apuesta pública por la planificación del territorio, con un perfil técnico que introdujo elementos progresistas novedosos. Se realizaron estudios diagnósticos para identificar los problemas y luego asociar la planificación a la gestión urbana y a la gestión directa de la obra pública ${ }^{19}$. Se creó el Consejo de Ordenamiento Urbano y Territorial (COUT) ${ }^{20}$ que llegó a erigirse en actor de consulta obligatoria ante todas las acciones que fueran a modificar el territorio, logró gran legitimidad dentro del Concejo Deliberante y del Poder Ejecutivo municipal. Se reformuló el Código de Ordenamiento Urbano para superar los problemas encontrados en la normativa anterior, pero además se pretendió trascender lo meramente técnico e introducir mecanismos de planificación estratégica, participación ciudadana e información pública. Sin salirse del rol de agente orientador de las acciones de otros actores de la ciudad -sobre todo, los privados- la nueva gestión abría la puerta a la participación ciudadana, al menos como intención ${ }^{21}$.

Una vez en vigencia el COU, se trabajó en lineamientos de acción territorial que en la actualidad -y a la luz de lo que sucedió posteriormente- se pueden calificar como decisiones progresistas, incluso de avanzada, en el campo del ordenamiento territorial en Argentina. Se mencionan a modo de ejemplos: la expresa prohibición de crear barrios cerrados cercanos al tejido urbano y su colocación periférica; el relevamiento del patrimonio arquitectónico existente y conformación de un Catálogo de Inmuebles Protegidos; la utilización del instrumento de transferencia de indicadores como mecanismo para la protección del patrimonio arquitectónico, sin afectar intereses de privados; la generación de convenios urbanísticos que implicaron la aprobación de cambios de usos en determinadas zonas sujetos al financiamiento de obras públicas ${ }^{22}$.

15 Durante el periodo estudiado, las ordenanzas que dictaron los CoU fueron: 4495/78, 9231/00 y 10703/10, aún vigente.

16 Intendencias de Juan C. Albertí y Pablo Pinto, Unión Cívica Radical.

17 Intendencias de Julio Alak, Partido Justicialista (4 gestiones).

18 Se armaron tres departamentos: Ordenamiento territorial, Planeamiento y Diseño urbano, más la secretaria técnica del COUT, desde su creación en 1997.

19 Se generaron mecanismos de licitación que agilizaban los tiempos para la ejecución presupuestaria de las partidas para obras públicas, mejorando su implementación.

20 Con representantes del Concejo Deliberante, de la Universidad Nacional de La Plata y de los Colegios Profesionales de Ingenieros y Arquitectos de la provincia.

21 El Régimen de información pública obligaba al municipio a abrir un registro con lo aprobado bajo el COU y posibilitar que se expresen las disconformidades, para ser respondidas antes de que la acción pudiera tener efectos jurídicos.

22 Por ejemplo, permisos a la instalación de hipermercados que financiaron la construcción de espacios públicos como la Plaza Islas Malvinas y la recuperación edilicia del Pasaje Dardo Rocha. 


\section{La ciudad entregada al lobby inmobiliario, 2007-2015}

Las últimas dos gobernaciones municipales fueron encabezadas por una corriente opuesta a la de la gestión anterior dentro del PJ. De su mano entraron a operar violentamente los intereses de los agentes inmobiliarios -los existentes y otros nuevos ${ }^{24}$ - ya sin intentos de orientación de sus acciones por parte del municipio, que los habilitó mediante decretos de excepción al COU y, desde 2010, bajo un nuevo Código planteado a la medida de los intereses privados y surgido de un proceso oscuro y muy denunciado ${ }^{25}$. La estructura de la DPU fue desmantelada y quedó en poco tiempo reducida a una dirección administrativa con poco personal y sin margen para emprender estudios y/o propuestas propias de gestión del territorio.

Los cambios en el COU se orientaron hacia una liberalización de las condiciones de acceso al suelo y una reducción de las exigencias urbanísticas a los promotores inmobiliarios, configurando un modelo de gestión urbana que tiende a maximizar las rentas de los desarrolladores en detrimento de beneficios sociales y ambientales en el proceso de urbanización. Pero además, el nuevo COU aseguró la permanencia de este modelo de gestión con la anulación del Consejo de Ordenamiento Urbano y Territorial y su reemplazo por el Consejo Único de Ordenamiento Territorial (CUOT) integrado por actores del sector de la construcción y del propio municipio ${ }^{26}$, y sin la presencia de la UNLP ni de ninguna otra entidad pública o ciudadana sin intereses sectoriales directos. También aumentó las atribuciones al Departamento Ejecutivo municipal para tomar decisiones en materia urbanística que excedan o contradigan lo establecido en los marcos normativos provinciales (Del Río y Relli, 2013).

Así quedó puesta de manifiesto la alianza entre la gestión municipal y el sector inmobiliario-constructor que no sólo estuvo representado por el pequeño grupo de grandes empresas promotoras que concentran el mercado, sino también por otros actores (constructores, agentes inmobiliarios, profesionales, técnicos) que, aún sin obtener las rentabilidades de los más grandes, han sacado provecho de esta lógica de producción de ciudad en un contexto macroeconómico favorable a la expansión de la actividad de la construcción. Se puede afirmar con Vértiz (2015) que durante esta gestión de gobierno "se produjo un amalgamiento entre retracción de capacidades técnicas, anulación de dispositivos de participación y hechos de inusitada discrecionalidad en ciertas decisiones de gestión urbana local" mientras que se acrecentaban las imposibilidades de acceso al suelo y la vivienda por parte de los sectores de ingresos medios y bajos.

\subsection{La ciudad informal: tratamiento e implementación de instrumentos de regularización}

A diferencia de lo comentado respecto de la política urbana y las funciones de la DPU, la intervención municipal en la política de regularización siguió un camino lineal hacia la consolidación de un perfil que posiciona al gobierno local como subsidiario de las iniciativas de los actores políticos del nivel provincial. Con una primera etapa de trabajo fuerte y en sintonía con organismos provinciales, otra de cierto retiro de la cuestión de la agenda política y una final de intentos de concreción de tareas pendientes, el tratamiento de la irregularidad se ha manejado siempre con medidas ex post que no han dado resultados satisfactorios tanto en la concreción de los procedimientos como en la eliminación del problema.

A mediados de la década del '90 se creó la Casa de Tierras, entidad formada en el marco de la adhesión provincial a la ley nacional de Titularización de Inmuebles ${ }^{27}$, desde donde se ensayaron procedimientos de regularización apelando a los instrumentos existentes. Con fuerte apoyo político local, fue convirtiéndose en una suerte de "consultorio" de problemáticas de irregularidad de la tenencia de la tierra y de puesta en marcha de distintos procedimientos en coordinación con organismos provinciales. Las acciones emprendidas desde la Casa de Tierras sostuvieron en jurisdicción municipal la lógica con la que se fueron concibiendo en el ámbito

23 Intendencias de Pablo Bruera, Partido Justicialista (2 gestiones).

24 Desde mediados de los '90 y en los primeros años del 2000, surgieron nuevos actores de fuerte peso en los segmentos de producción y comercialización de inmuebles, con gran poder de lobby a nivel local, que consolidaron una posición central en el mercado inmobiliario y son responsables de gran parte de los cambios en la fisionomía de la ciudad, a las que se suman más de un centenar de empresas de menor porte, beneficiadas por los procesos abiertos gracias a la permeabilidad del gobierno a las demandas de los grandes desarrolladores (Del Río y Relli, 2013).

25 Se denunció la falta de discusión sobre la reforma del COU (lo cual no sucedió ni en el Concejo Deliberante) y la elusión de los mecanismos previstos en ordenanzas anteriores (Del Río y Relli, 2013). El COU fue convalidado en la instancia provincial con más de 30 artículos observados (Decreto 466/11).

26 Representación del Concejo Deliberante, del Departamento Ejecutivo y de colegios profesionales de la provincia de Buenos Aires: Ingenieros, Arquitectos, Agrimensores y Técnicos.

27 Las Casas de Tierras fueron organismos híbridos (provinciales y municipales) cuya función era informar a la población sobre los requisitos para acceder a la titulación de los inmuebles mediante la LN 24374. En Buenos Aires, la implementación del procedimiento está terciarizada en los Registros Notariales de Regularización Dominial (RNRD), entidades privadas coordinadas por el Colegio de Escribanos de la provincia (Decretos 3991/94 y 2815/96). 
de la provincia a lo largo de los años y conforme aumentaba la irregularidad del hábitat popular: la definición del problema se centraba en la dimensión dominial de la irregularidad y las acciones procuraban radicar a la población mediante actos de intermediación pública y financiamiento subvencionado de la adquisición de la tierra ya habitada. A la dimensión urbanística se la concebía casi en la totalidad de los casos como obstáculos a sortear mediante excepciones.

Este organismo fue parido sin relaciones con la DPU y los conflictos con los actores públicos de perfil técnico no tardaron en manifestarse, puesto que lo que se encaraba desde la Casa de Tierras eran medidas que se salen de la lógica de la planificación territorial y que suelen ir en contra de ella: se legalizan situaciones de hecho que han surgido fuera de la norma y de las prescripciones técnicas que han pretendido direccionar el rumbo de la ciudad. Las urbanizaciones populares suelen darse sobre suelo vacante periférico, es decir, aquellos vacíos cuyos propietarios no movilizan (por presentar problemas ambientales que requieren inversiones fuertes para habilitar, por mantenerlos en espera especulativa, por problemas de titularidad, etc.) y se presentan a las familias como oportunidades de acceso al suelo (a través de la participación en una ocupación o de compraventas en loteos producidos por agentes ilegales). La regularización va a ir a posteriori -y en nombre de los derechos de los/as habitantes- a incluir dentro de la norma lo producido violándola. He aquí el conflicto estructural, al que puede sumarse el choque de personalidades, liderazgos y maneras de concebir la acción política dentro de la gestión pública, que también explican la conformación de dos vías paralelas y sin vínculos en la gestión territorial de lo formal y de lo informal. Desde la intendencia se hizo lugar a la convivencia de ambas lógicas, puesto que fue parejo el apoyo brindado a las iniciativas de la DPU y de la Casa de Tierras, y se sentaron las bases del tratamiento de la cuestión a partir de esas dos ventanillas.

El trabajo fuerte de la Casa de Tierras en La Plata reflejó el periodo de fuerte vigencia del problema del acceso a la tierra en la agenda del gobierno provincial. Pero ya a principios de la década de 2000 perdió peso y recién volvió a instalarse, desde iniciativas de actores políticos locales, a fines del periodo estudiado, cuando se retomó la implementación de la ley 24374 y se avanzó con la escrituración de viviendas construidas por el IVBA, en intentos por reposicionar la cuestión en la agenda de gobierno y ante el evidente crecimiento de la irregularidad.

\section{A continuación se presentan los casos atendidos con instrumentos de regularización:}

Las posesiones irregulares de tierra de dominio privado del Estado se abordaron en todos los casos mediante la transferencia en venta de los lotes, de allí el mote de Estado vendedor. Para ello, se utilizaron los instrumentos que se mencionan en el cuadro 2, donde también se puede observar el escaso nivel de concreción de los procedimientos.

\begin{tabular}{|c|c|c|c|c|c|}
\hline Acceso & Barrio / Localidad & Dominio & Encuadre regularización & Inicio & Resultados \\
\hline \multirow{6}{*}{ Ocupación } & $\begin{array}{l}\text { Lotes de reserva vendidos a } \\
\text { ocupantes. Parcelas dispersas }\end{array}$ & municipal & $\begin{array}{l}\text { DL } 9533 / 80 \text { y dec. } 2210 / 80 \\
\text { Ley } 13148 / 04 \text { (exime normativa urbanística) }\end{array}$ & $\begin{array}{l}\text { fines decada } \\
\text { del " } 80\end{array}$ & $40 \%$ finalizado \\
\hline & $\begin{array}{l}\text { Barrio sin nombre } \\
\text { Altos de San Lorenzo }\end{array}$ & provincial & $\begin{array}{l}\text { Ley } 10862 \text { (de transferencia a sus } \\
\text { ocupantes) }\end{array}$ & 1989 & finalizado \\
\hline & $\begin{array}{l}\text { La Bajada/Autopista } \\
\text { Ringuelet }\end{array}$ & municipal & Subprog. Villas y Asentamientos - PFV & 2004 & inconcluso \\
\hline & \begin{tabular}{|l} 
La Laguna \\
Ringuelet
\end{tabular} & provincial & Subprog. Villas y Asentamientos - PFV & 2004 & inconcluso \\
\hline & \begin{tabular}{|l} 
La Unión \\
Ringuelet
\end{tabular} & municipal & Subprog. Villas y Asentamientos - PFV & 2004 & inconcluso \\
\hline & $\begin{array}{l}\text { El Mercadito } \\
\text { Rinquelet }\end{array}$ & municipal & Subprog. Villas y Asentamientos - PFV & 2004 & inconcluso \\
\hline \begin{tabular}{|l|} 
Cesion con \\
pago de \\
canon
\end{tabular} & $\begin{array}{l}\text { Barrio Hipodromo } \\
\text { Casco }\end{array}$ & provincial & Ley 11418 & 2000 & finalizado 2004 \\
\hline
\end{tabular}

Cuadro 2. La Plata: tierra de dominio público y procedimientos de regularización

Elaboración propia en base a entrevistas y revisión de leyes y documentos públicos.

Frente a las ocupaciones y/o compraventas irregulares de tierra de dominio privado, los instrumentos utilizados han sido tres, la sanción de leyes de expropiación, la prescripción administrativa y la condonación de deuda inmobiliaria a cambio de tierra con fines de utilidad social. En los tres procedimientos, el gobierno provincial se hace de la titularidad del bien para luego transferirlo en venta financiada a largo plazo a sus ocupantes, de allí su rol de Estado mediador.

El instrumento más utilizado para enfrentar las ocupaciones de tierra privada ha sido la sanción de leyes de expropiación, se dictaron 16 leyes entre 1995 y 2015, de las cuales sólo 6 han superado la etapa de cambio de titularidad (expropiación propiamente dicha) y están en condiciones de avanzar en la transferencia a ocupantes, lo cual no habla por sí mismo de la culminación del procedimiento (cuadro 3). La situación 
expuesta para el partido de La Plata se repite crudamente en el AMBA, demostrando que la sanción de leyes de expropiación suele frenar desalojos judiciales y desplazar temporalmente la resolución del problema, pero no incide verdaderamente en la regularización de los asentamientos.

La prescripción administrativa ${ }^{28}$ y la condonación de deudas impositivas a cambio de la cesión de inmuebles que luego se destinarán con fines de solidaridad social ${ }^{29}$ se utilizaron en los otros cuatro casos atendidos, pero ninguno se ha logrado concretar, tal como lo muestra el cuadro 4.

\begin{tabular}{|c|c|c|c|c|c|c|}
\hline \multirow{2}{*}{$\begin{array}{l}\text { Período en el } \\
\text { que fueron } \\
\text { sancionadas }\end{array}$} & \multirow{2}{*}{\begin{tabular}{|l|}
\multicolumn{1}{|c|}{ Procedimiento avanzado } \\
$\begin{array}{l}\text { avenimiento expropiatorio o sentencia } \\
\text { judicial positiva }\end{array}$ \\
\end{tabular}} & \multicolumn{4}{|c|}{ Procedimiento inconcluso } & \multirow[t]{2}{*}{ Total } \\
\hline & & $\begin{array}{l}\text { en juicio o sentencia judicial } \\
\text { negativa }\end{array}$ & $\begin{array}{l}\text { problemas } \\
\text { urbanisticos }\end{array}$ & $\begin{array}{l}\text { declarada en } \\
\text { abandono }\end{array}$ & $\begin{array}{l}\sin \\
\text { movimiento }\end{array}$ & \\
\hline 1995-1999 & $\begin{array}{l}\text { La cumbre (San Carlos) } \\
\text { Circunvalación (Altos de San Lorenzo) }\end{array}$ & Sin nombre (San Carlos) & & $\begin{array}{l}\text { Sin nombre } \\
\text { (Villa Elvira) }\end{array}$ & & 4 \\
\hline $2000-2009$ & $\begin{array}{l}\text { Puente de Fierro (Altos de San Lorenzo) } \\
\text { Mercosur (Hernández) }\end{array}$ & $\begin{array}{l}\text { La Aceitera (Arana) } \\
\text { La Esperanza (Los Hornos) } \\
\text { La Esperanza II (Los Hornos) }\end{array}$ & $\begin{array}{l}\text { Malvinas II } \\
\text { (M. Romero) }\end{array}$ & & & 6 \\
\hline $2010-15$ & $\begin{array}{l}\text { Puente de Fierro II (Altos de San Lorenzo) } \\
\text { Sin nombre (Abasto) }\end{array}$ & $\begin{array}{l}\text { La Cantera (Hernández) } \\
\text { San Cayetano (M. Romero) }\end{array}$ & $\begin{array}{l}\text { Villa Alegre } \\
\text { (Villa Elvira) }\end{array}$ & & $\begin{array}{l}\text { La Palmeras } \\
\text { (Los Hornos) }\end{array}$ & 6 \\
\hline Totales & 6 & 6 & 2 & 1 & 1 & 16 \\
\hline
\end{tabular}

Cuadro 3. La Plata: estado de avance de los procedimientos de regularización a partir de leyes de expropiación (barrio/localidad)

Elaboración propia en base a información de la Fiscalía de Estado, la SSTUV y entrevistas.

\begin{tabular}{|l|l|l|l|}
\hline Barrio/Localidad & Características, instrumentos & Inicio regularización & Estado del procedimiento \\
\hline $\begin{array}{l}\text { Gambier } \\
\text { Los Hornos }\end{array}$ & $\begin{array}{l}\text { Una manzana atravesada por vías del ffcc. } \\
\text { Prescripción adquisitiva y ordenamiento } \\
\text { parcelario mediante decreto 3736/91 }\end{array}$ & Década del '90 & $\begin{array}{l}\text { inconcluso } \\
\text { plano sin aprobar por } \\
\text { invasión de calle }\end{array}$ \\
\hline $\begin{array}{l}\text { Padre Cajade } \\
\text { Arana }\end{array}$ & Prescripción adquisitiva & $\begin{array}{l}\text { inconcluso } \\
\text { falta plano }\end{array}$ \\
\hline $\begin{array}{l}\text { Cavalaro } \\
\text { Los Hornos }\end{array}$ & $\begin{array}{l}\text { Venta irregular de terrenos en macizo; posterior } \\
\text { adquisición por usucapión para transferencia a } \\
\text { ocupantes (compradore/as irregulares) }\end{array}$ & Década 2010 & $\begin{array}{l}\text { inconcluso } \\
\text { falta plano }\end{array}$ \\
\hline $\begin{array}{l}\text { La Piedad } \\
\text { Los Hornos }\end{array}$ & Ley 11622 & Década 2010 & inconcluso \\
\hline
\end{tabular}

Cuadro 4. La Plata: regularización por prescripción administrativa y ley 11622

Elaboración propia en base a entrevistas y revisión de leyes documentos públicos.

Se ha rotulado como Estado escriturador a las intervenciones que suponen erogación de recursos para legalizar las tenencias de inmuebles. Las dos líneas de trabajo más importantes en este sentido son la implementación de la Ley Nacional de Titularización de Inmuebles ${ }^{30}$ y la regularización y escrituración de viviendas construidas por el IVBA ${ }^{31}$.

La Ley Nacional de Titularización de Inmuebles se implementa en dos etapas: la entrega de un acta de regularización y, pasados diez años, la consolidación del acta en escritura ${ }^{32}$. La tramitación en cualquiera de las dos instancias se realiza de manera individual/personal y a través de los Registros Notariales de Regularización Dominial, pero desde el municipio también se ha colaborado a través de salidas a los barrios para brindar información, visar documentación, etc. en definitiva, darle el impulso político a un instrumento que, cuando se puso en marcha, terciarizó su ejecución. En La Plata se entregaron 4.385 actas de regularización entre 1996 y 2013 (el 85\% de ellas en los primeros años de implementación de la ley), sólo el $18,6 \%$ del total de actas entró en proceso de consolidación y el 11,5\% lo había finalizado a mediados de 2013 (gráfico 5.3).

32 A su vez, la consolidación presenta tres fases: inicio del trámite, firma de escritura e inscripción de la escritura en el Registro de la Propiedad. 


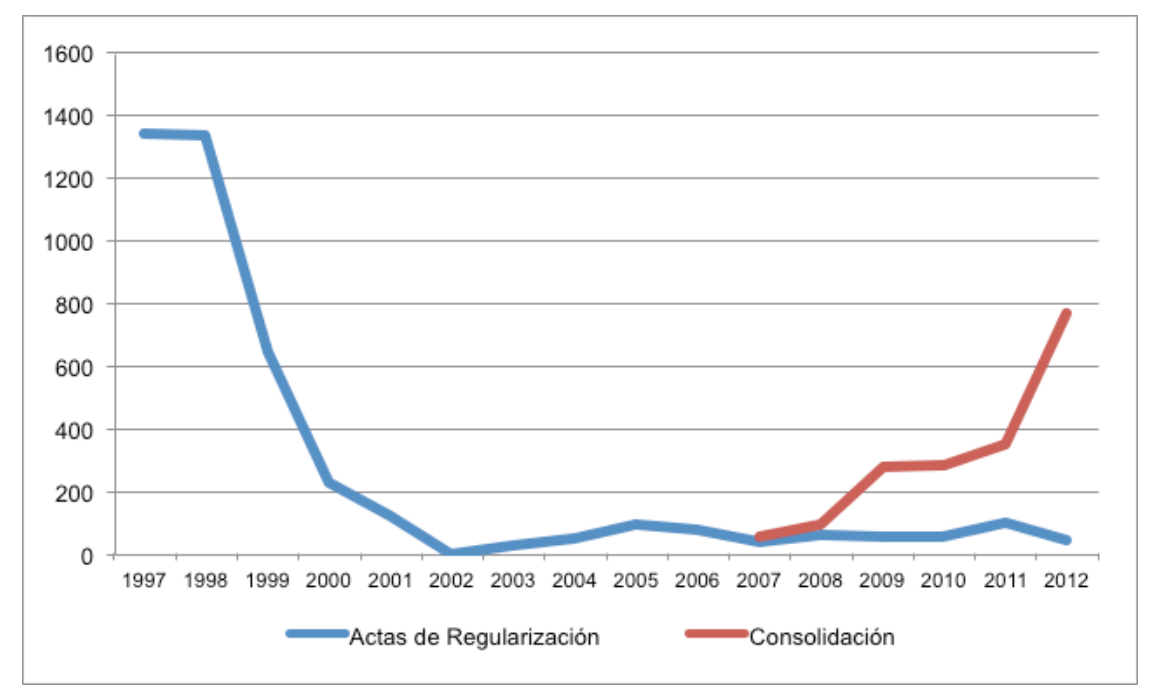

Gráfico 3. La Plata: implementación de la Ley Nacional de Titularización de Inmuebles Elaboración propia en base a datos del Colegio de Escribanos de la Provincia de Buenos Aires.

En La Plata se notó el impacto de la decisión política provincial de abordar la cuestión de la falta de escrituras en las viviendas públicas. La sanción de un Decreto que posibilitó aceptar como beneficiario/as de la titularización a quienes habiten la vivienda al momento del censo ad hoc (más allá de la forma en la que hubieran accedido a ella o de quiénes fueran los beneficiarios originales), permitió destrabar uno de los principales problemas que se enfrentan en los procesos de regularización (y que, para los demás casos, continúa sin resolverse): la movilidad y los cambios de composición de las familias y las compraventas irregulares de viviendas sociales. Con la intervención conjunta del municipio y de la provincia (Dirección de Regularización y Dirección Provincial de Inmobiliario y Social del IVBA, respectivamente), se llevó el porcentaje de viviendas escrituradas desde el 35 al 93\% entre 2010 y 2016 (cuadro 5).

\begin{tabular}{|c|c|c|c|}
\hline Viviendas sociales & Escrituradas hasta 2009 & Escrituradas 2010-16 & Total escriturado \\
\hline 7.908 & 2.799 & 4.537 & 7.336 \\
\hline $100 \%$ & $35 \%$ & $57 \%$ & $93 \%$ \\
\hline
\end{tabular}

Cuadro 5. La Plata. Escrituración de viviendas del IVBA

Elaboración propia en base a datos de la Dirección de Inmobiliario y Social, IVBA.

Mención aparte merecen las viviendas construidas en el marco del Plan Federal de Viviendas, entre 2003 y 2007: el ya mencionado conjunto de barrios de Ringuelet (Subprograma de Villas y Asentamientos) y la culminación de un antiguo y abandonado conjunto de viviendas en la localidad de Tolosa (Av. 19 y 526). Ambos casos estuvieron atravesados por apuros electorales, disputas políticas entre fracciones del partido gobernante a nivel municipal y situaciones de violencia. Los barrios de Ringuelet se construyeron y se entregaron las viviendas, pero no se realizaron los planos de final de obra y, por lo tanto, no se puede avanzar en su regularización dominial. En el barrio de Tolosa hubo superposición de listas de beneficiario/as debido a manejos clientelares de los funcionarios públicos, a lo que se sumó la ocupación violenta de parte de las viviendas. Su regularización quedó paralizada por las dificultades para llevar adelante los procedimientos en un clima de hostilidad y violencia intrabarrial, y por la falta de dispositivos públicos para dar tratamiento a ese tipo de situaciones de gran complejidad social. La escrituración de viviendas del IVBA, de éxito evidente en los últimos años, se vio contrarrestada por la producción irregular de viviendas sociales, problema que el mismo Estado tendrá que resolver en el futuro.

La información sobre los resultados generales de los procedimientos de regularización muestra bajos niveles de concreción. Aun los que a priori pueden aparecer como los más sencillos de resolver, como las transferencias de tierras de dominio público, han tenido que enfrentarse con obstáculos que los han retrasado $y$, como consecuencia de ello, sumado nuevas irregularidades producto de las modificaciones en la composición de las familias, su movilidad y las compraventas irregulares que suelen acompañarla (Relli 2017). Pero además, una somera lectura sobre el despliegue territorial de las medidas, muestra el alcance limitado de la regularización respecto del dinamismo de la producción de hábitat popular, expresada en el mapa 3 con el emplazamiento de las villas y asentamientos (donde se presentan mayoritaria, pero no únicamente, las situaciones de irregularidad) y de los instrumentos utilizados. 


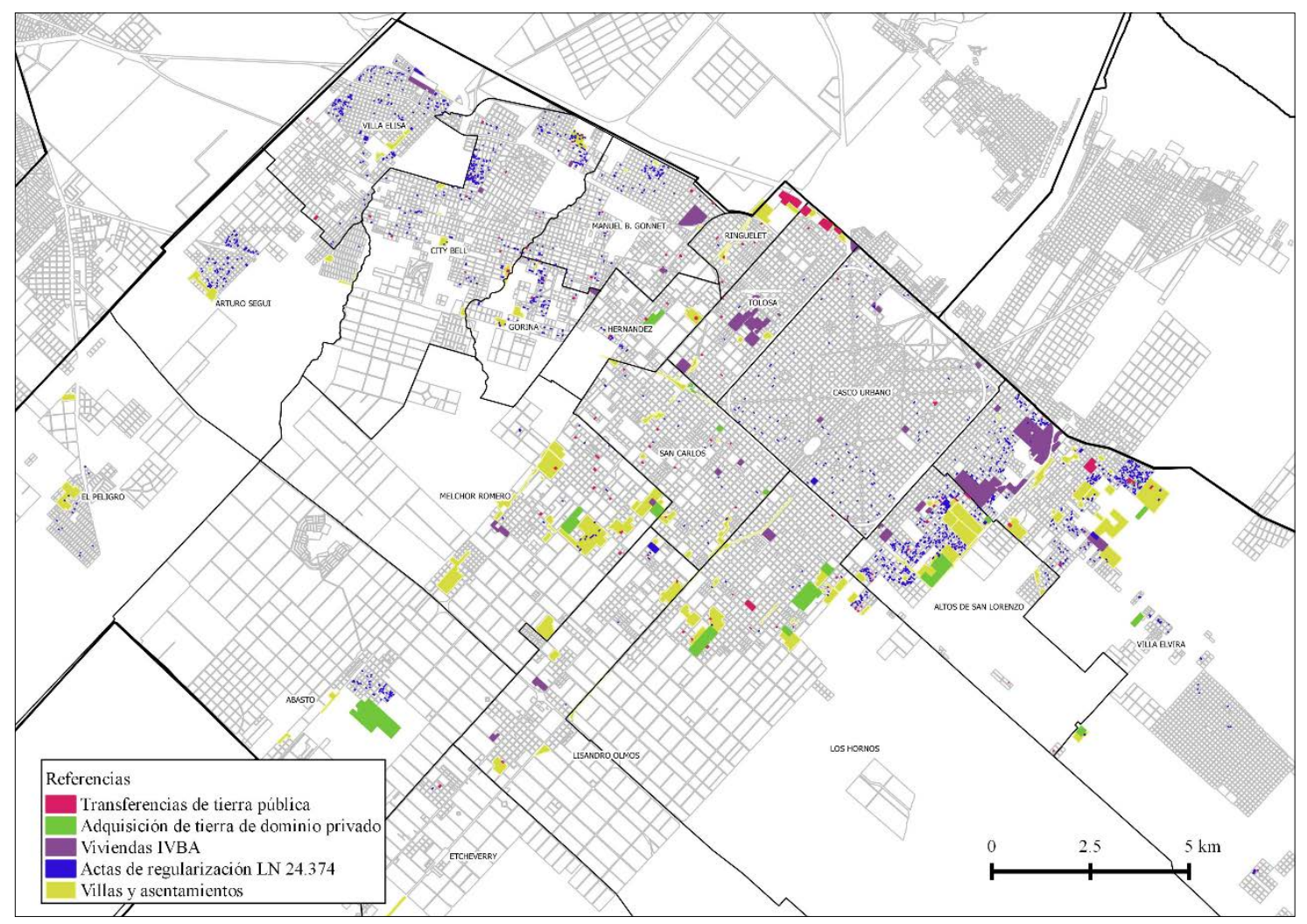

Mapa 3. La Plata. Instrumentos de regularización y su anclaje territorial; villas y asentamientos Elaboración propia en base al RPPVAP (2015), información del Colegio de Escribanos de la provincia de Buenos Aires, revisión de leyes, decretos, documentos oficiales y entrevistas.

\section{CIUDAD FORMAL, CIUDAD INFORMAL: GESTIONES PARALELAS Y SIN DIÁLOGO}

La tardía aparición del problema de la irregularidad del hábitat popular urbano en La Plata, invita a pensar que las gestiones municipales desde la recomposición de la democracia en 1983 podrían haber intentado medidas preventivas que apunten a la oferta accesible de suelo de buena calidad urbanística, incluso a tratamientos particularizados de situaciones que, hasta entrados los años '90, aparecían a modo de casos puntuales y reducidos. Pero el problema de la irregularidad del hábitat popular ingresó en la agenda municipal una vez consolidada la ausencia de política sectorial para facilitar el acceso al suelo urbano de los sectores populares, cuestión que se presenta con crudeza porque La Plata ha sido un municipio con los recursos económicos, territoriales y humanos (políticos y técnicos) para encauzar de otro modo el proceso de urbanización e incluso porque sus referentes políticos han mantenido una fuerte connotación discursiva que valoriza el nacimiento planificado de la ciudad, destacando de ese modo la importancia del rol del Estado y sus actores técnico-políticos. Pero el acceso al espacio residencial de (cada vez más) amplios sectores de la población, no estuvo contemplado dentro de las tareas del planeamiento urbano. El tratamiento de la irregularidad resultante de la producción popular de hábitat se empalmó con las medidas que se iban perfilando en el nivel provincial de gobierno, bajo la lógica de la acumulación política y sin ningún anclaje en la política urbana municipal.

En La Plata, a la porción formal de la ciudad la fue configurando fundamentalmente el mercado inmobiliario, bajo la relativa supervisión del municipio. Se observó a inicios de los ' 90 el pasaje desde la acción municipal meramente técnica (inspección de las iniciativas privadas y públicas) hacia una actitud proactiva respecto de la planificación urbana y sus posibilidades de orientación del crecimiento de la ciudad formal, pero que se desarrolló en forma paralela y hasta divorciada de la gestión de un hábitat popular que se incrementaba sostenidamente. Aún en el período en el que se identifica un posicionamiento progresista de la política urbana y sus obligaciones (1991-2007), desde la gestión pública no se lograron identificar las relaciones de causalidad entre la producción del espacio residencial bajo lógicas de acumulación de ganancias y el alejamiento de las posibilidades de satisfacción de necesidades de los sectores de ingresos bajos. El planeamiento diseñado para atender únicamente a los agentes privados y estatales en la producción de 
espacio urbano, ignoró las consecuencias de su desempeño a nivel general, sobre todo, en lo relativo al encarecimiento del acceso al suelo como producto de la valorización propia de las inversiones (públicas y privadas) y de los cambios en las asignaciones de usos del suelo. La extensión de los asentamientos irregulares no llegó a posicionarse en la agenda estatal local como un fenómeno a atender desde sus causas y desde su íntima relación con el funcionamiento general de los submercados de suelo, vivienda y alquiler. El municipio asumió al respecto un rol de mero apoyo para la implementación de las iniciativas construidas en el nivel provincial, cuya orientación obedeció desde el principio a las intenciones de dar respuesta a demandas sociales de manera puntual (coyuntural), sin la implementación de instrumentos de atención ex ante de las necesidades sociales de suelo y vivienda. El hecho de alojar ambas formas de tratamiento de la producción de ciudad denota una fuerte contradicción que hasta hoy se paga con la sostenida expansión del hábitat irregular, producto de la demanda creciente e insatisfecha.

Hacia el final del período estudiado, cuando la entrega de la ciudad a los intereses privados se profundizó (junto al desmantelamiento de funciones de supervisión y orientación de los agentes productores de ciudad), también se consolidó ese rol municipal de acompañamiento a las medidas correctivas, sin cabida a iniciativas preventivas. Todo esto con el agravante de un contexto de expansión de la demanda derivada de suelo urbano como objeto de colocación de excedentes financieros para su valorización y de la reforma del COU a la medida de los intereses inmobiliarios, cuestiones que extremaron las consecuencias propias del funcionamiento del mercado de suelo desregulado: aumento exponencial del precio de los inmuebles y ensanchamiento de la brecha urbana (Del Río, Langard y Arturi, 2014; Del Río, Langard y Relli 2014).

La consolidación de dos ventanillas desde donde la gestión pública encara el ordenamiento territorial -la de la ciudad formal y la de la ciudad informal- ha cristalizado en un andamiaje institucional que refuerza el tratamiento ex post de la irregularidad, sin atender sus causas, lo cual también revierte en las demandas de lo/as pobladore/as, alimentando un circuito de medidas-demandas-medidas que no solucionan el problema, sino que lo agravan. Parte de la explicación radica en la distribución de competencias entre niveles de gobierno. En ocasiones, la actividad desplegada en territorio municipal por organismos provinciales condiciona y encorseta las decisiones de la gestión local, por ejemplo, cuando se transfiere tierra a sus ocupantes (mediante distintos mecanismos) asignándole un uso residencial a esa porción de suelo que no necesariamente va a estar emplazado en un área de expansión residencial; en esos casos, el municipio pierde la capacidad de oponerse, sobre todo, por el costo político que podría significarle el no otorgar el cambio de uso para ello. Y allí entran en juego las lógicas de acumulación política desde las cuales se han concebido y mantenido las políticas de regularización. Pero la cuestión central debe enfocarse en la ausencia de medidas reguladoras del funcionamiento del mercado de suelo (captación y redireccionamiento de las plusvalías generadas en el proceso de urbanización, restricciones a los comportamientos especulativos, entre otras), principal causa del alejamiento de posibilidades de acceso al suelo y, por consiguiente, de la irregularidad urbana. Y allí, la gestión municipal podría haber intervenido.

La política de regularización es un ejemplo de política de Estado que ha trascendido gobiernos y cuya orientación se ha profundizado, pero a pesar de la continuidad y de sus intenciones manifiestas de corregir lo que se ha producido por fuera de la normativa, la producción de ciudad en la irregularidad ha sido más veloz y ha opacado los magros resultados de las acciones ex post. A ello ha contribuido la consolidación de la hegemonía del mercado de suelo como mecanismo coordinador del crecimiento urbano y la insistencia en las recetas correctivas que no tocan las causas de la producción de ciudad irregular, para lo cual se tornaría imprescindible el diálogo con la política urbana.

\section{BIBLIOGRAFÍA}

Abramo, P. (2011). La producción de las ciudades latinoamericanas: mercado inmobiliario y estructura urbana. Ecuador: OLACCHI-FLACSO.

Azuela, A. (1989). La ciudad, la propiedad privada y el derecho. México: El Colegio de México.

Clichevsky, N. (2003). Pobreza y acceso al suelo urbano. Algunos interrogantes sobre las políticas de regularización en América Latina. Santiago de Chile: CEPAL.

Clichevsky, N. (2006). Previniendo y regularizando la informalidad del suelo en América Latina. Marco legal. Santiago de Chile: CEPAL. 
Connolly, P. (2013). La ciudad y el hábitat popular: paradigma latinoamericano. En Ramirez, B. y Pradilla, E. (comp). Teoría sobre la ciudad en América Latina. México: UAM.

Cravino, M.C. (Org.) (2008). Los mil barrios (in)formales. Aportes para la construcción de un observatorio del hábitat popular del Área Metropolitana de Buenos Aires. Los Polvorines: UNGS.

Del Río, J.P. y González, P. (2017). Los asentamientos informales en el Gran La Plata. Una geografía cambiante con más de tres décadas de persistencia. En Cravino, M.C. (Comp.). La ciudad negada. Aproximaciones al estudio de asentamientos populares de 10 ciudades argentinas. Los Polvorines: UNGS.

Del Río, J.P. y Relli, M. (2013). Concentración de la oferta inmobiliaria y nuevos agentes en el Gran La Plata. Actas IV Congreso Nacional de Geografía de Universidades Públicas y XI Jornadas Cuyanas de Geografía, Mendoza, octubre, formato digital.

Del Río, J.P., Langard, F. y Arturi, D. (2014). La impronta del mercado inmobiliario en el período neodesarrollista. Realidad Económica, 283.

Del Río, J.P., Langard, F. y Relli, M. (2014). Mercado inmobiliario y acceso a la ciudad: ¿por qué no bajan los precios como anunció el sector inmobiliario-constructor platense? Actas Terceras Jornadas Nacionales de Investigación y Docencia en Geografía Argentina, Tandil (formato digital).

Duhau, E. (1998). Hábitat y política urbana. México: UAM.

Duhau, E. (2002). Dimensiones socio-políticas de la irregularidad y la regularización de los asentamientos populares. Curso de desarrollo profesional sobre Mercados informales, regularización de la tenencia y programas de mejoramiento urbano en América Latina. LILP.

Fernandes, E. (2008). Consideraciones generales sobre las políticas públicas de regularización de asentamientos informales en América Latina. EURE, XXXIV, 102.

Fernandes, E. (2012). Una lectura crítica de Hernando de Soto. En Salazar, C. (Coord.). Irregular. Suelo y mercado en América Latina. México: El Colegio de México.

Garnier, A. (1995). Los espacios públicos de La Plata: de la tradición a la modernidad. En AA.VV. La Plata: de la ciudad antigua a la ciudad nueva. Sueños y realidades. La Plata: LINTA/CIC y Municipalidad de La Plata.

Herzer, H.; Di Virgilio, M.; Redondo, A. y Rodríguez, M.C. (2008). ¿Informalidad o informalidades? Hábitat popular e informalidades urbanas en áreas urbanas consolidadas (Ciudad de Buenos Aires, Argentina). Pampa, 4.

Jaramillo, S. (2008). Reflexiones sobre la 'informalidad' fundiaria como peculiaridad de los mercados de suelo en las ciudades de América Latina. Territorios, 18-19.

Jaramillo, S. (2009). Hacia una teoría de la renta del suelo urbano. Bogotá: Universidad de los Andes.

Jaramillo, S. (2012). Urbanización informal: diagnóstico y políticas. Una revisión al debate latinoamericano para pensar líneas de acción actuales. En Salazar, E. (Coord.) (2012). Irregular. Suelo y mercado en América Latina. México: El Colegio de México.

Oszlak, O. (1991). Merecer la ciudad. Los pobres y el derecho al espacio urbano. Buenos Aires: CEDESHumanitas.

Pírez, P. (1995). Actores sociales y gestión de la ciudad. Ciudades, 28.

Pírez, P. (2016). Las heterogeneidades en la producción de la urbanización y los servicios urbanos en América Latina. Territorios, 34.

Relli Ugartamendía, M. (2016). Tres décadas de intentos de regularizar el hábitat popular urbano en la provincia de Buenos Aires, Argentina. Actas Jornadas de Doctorado en Geografía, FaHCE, UNLP.

Relli Ugartamendía, M. (2017). Estado regularizador y generador de irregularidad del hábitat popular urbano. El caso de La Plata, provincia de Buenos Aires. Actas VI Congreso Nacional de Geografía de Universidades Públicas, Resistencia, formato digital.

Resa, S. (Coord.) (1995). Ideas para un nuevo régimen legal de planeamiento urbano. La Plata: Municipalidad de La Plata. 
Rodríguez M.C. y Di Virgilio, M.M. (2007): Políticas del hábitat, desigualdad y segregación socioespacial en el Área Metropolitana de Buenos Aires. Buenos Aires: AEU/IIGG.

Rodríguez, M.C. y Di Virgilio, M.M. (comps.) (2011). Caleidoscopio de las políticas territoriales: un rompecabezas para armar. Buenos Aires: Prometeo.

Rolnik, R. (2007). A cidade e a lei: legislação, política urbana e territorios na cidade de São Paulo. Sao Paulo: Studio Nobel FAPESP.

Salazar, E. (Coord.) (2012). Irregular. Suelo y mercado en América Latina. México: El Colegio de México.

Schteingart (2001). Los productores del espacio habitable: Estado, empresa y sociedad en la Ciudad de México. México: El Colegio de México.

Sessa, E. (1995). La Plata y el contexto internacional. En AA.VV. La Plata: de la ciudad antigua a la ciudad nueva. Sueños y realidades. La Plata: LINTA/CIC y Municipalidad de La Plata.

Vértiz, F. (2015). Intervención estatal en la producción de la ciudad. Conformación y orientación de la política urbana en el partido de La Plata (2003-2014). Tesis de Doctorado, FaHCE, UNLP. 